\title{
Simulated groundwater interaction with rivers and springs in the Heihe river basin
}

\author{
Li-Tang Hu, ${ }^{1 *}$ Chong-Xi Chen, ${ }^{2}$ Jiu Jimmy Jiao ${ }^{3}$ and Zhong-Jing Wang ${ }^{1}$ \\ ${ }^{1}$ Institute of Hydrology and Water Resources, Department of Civil Engineering, Tsinghua University, Beijing, P.R. China \\ ${ }^{2}$ Institute of Environmental Geology, China University of Geosciences, Wuhan, P.R. China \\ ${ }^{3}$ Department of Earth Sciences, University of Hong Kong, Pokfulam Road, Hong Kong, P.R. China
}

\begin{abstract}
:
Surface water and groundwater in the Heihe river basin of China are interconnected and the pattern of water resources exploitation has a direct effect on the interaction of groundwater and surface water, especially on a downstream oasis. A threedimensional groundwater flow simulation model with eight model layers was established to simulate the regional groundwater flow in the multilayered aquifer system and the interaction among the rivers, springs, and groundwater. The model was calibrated not only with historical water levels but also with the investigated baseflow and spring flux. The simulation results of the numerical model match reasonably well with the observed groundwater levels, baseflow to rivers, and spring flux. The numerical simulation also demonstrates that the hydraulic connection between the river and the aquifers has transferred from the coupling to decoupling at some reaches. It is suggested that there is a vital need to reduce groundwater withdrawal and to rationalize the use of both groundwater and surface water in order to maintain sustainable development in the study area. Copyright (c) 2007 John Wiley \& Sons, Ltd.
\end{abstract}

KEY WORDS numerical simulation; groundwater/surface-water relations; groundwater flow; arid regions; springs

Received 11 January 2006; Accepted 16 June 2006

\section{INTRODUCTION}

The middle reaches of the Heihe river basin are located in the middle section of the Hexi corridor in China, and were once part of the famous 'silk route' between China and the West during the period of the Han dynasty. With the intensity of human activities, the demand for water, especially for agricultural purposes, has increased rapidly in recent times, and both surface water (including rivers and springs) and groundwater have been exploited. The pattern of water resources exploitation has had a direct impact on the area of the delta oasis downstream of the Heihe river basin, where the Heihe River is the main source of recharge. Interactions between surface water and groundwater have gained more and more attention (Sear et al., 1999; Sophocleous, 2002; Rushton, 2003). A careful study of the dynamic interaction between surface water and groundwater will provide some guidelines for reasonable water resources exploitation and prevention of regional ecological environment from further degradation.

In the study area, groundwater may discharge directly into rivers or discharge in the form of springs, which then join rivers. A spring is a natural resurgence of groundwater and can provide important information that allows

\footnotetext{
* Correspondence to: Li-Tang $\mathrm{Hu}$, Institute of Hydrology and Water Resources, Department of Civil Engineering, Tsinghua University, Beijing, P.R. China. E-mail: hulitang@tsinghua.org.cn
}

for better understanding of the hydrogeological conditions. Springs can be classified into gravity springs and artesian springs according to the characteristics of the source aquifer. A key issue in this study is how to represent interaction between groundwater, rivers, and springs numerically in the model. Springs have been widely studied by previous researchers using various approaches, which include analytical methods (Atkinson, 1977; Bhar and Mishra, 1997; Swanson and Bahr, 2004), statistical analysis (Jian et al., 1998; Carol and John, 2000) and numerical modeling (Chen, 1995; Hunt, 2003; Swanson and Bahr, 2004). The analytical method is of limited use because it is usually under very strict assumptions. The statistical analysis is to establish the correlation function among factors affecting spring flux. The relationship may be linear (Jian et al., 1998) or non-linear (Carol and John, 2000). In the numerical model, a spring could be treated as prescribed head boundary (Chen, 1995), which treats the elevation of the spring outlet as groundwater head, flux boundary or drain (Hunt and Steuer, 2001; Swanson and Bahr, 2004). When springs are treated as flux boundary, we need to specify the flux before the simulation, while if springs are treated as drains, it could be time consuming to solve the associated nonlinear equation. A regional hydrogeological system is always heterogeneous. When spring flow is involved, especially in a karst aquifer system, flow in the spring vent can be non-Darcian. Chen (1995); Chen and Jiao (1999) presented an equivalent hydraulic conductivity (EHC) approach to integrate groundwater flow in porous media, fractures, and conduits (pipe flows). Details of 
this approach can be found in Chen and Jiao (1999). A similar approach can also be found in Angelini and Dragoni (1997). The EHC approach was used in this study to handle spring flow. The interaction between groundwater and rivers have been studied by using isotope methods (Hamada, 1999), statistic analysis (Grapes et al., 2005), or numerical models (Hunt, 2003; Negrel et al., 2003). These researchers use either an uncoupled groundwater flow model (Eldin et al., 2000) or a coupled numerical groundwater flow model with a streamflow routing package to determine the base flow (Swain and Wexler, 1996). The problem of model validity exists due to the heterogeneous nature of the aquifer and lack of data. This paper attempts to develop a relatively accurate numerical model to analyse the interaction between groundwater, rivers, and springs, based on all available data.

\section{GEOLOGICAL AND HYDROGEOLOGICAL CONDITIONS}

The study area (shown in Figure 1) is a sedimentary basin surrounded by the Qilian mountain in the south, the Bei mountain in the north, and is adjoined with another river basin in the eastern region. The boundary to the west is set to be the water divide between the adjoining basins. The elevation decreases from north to south and west to east from 2200 to $1290 \mathrm{~m}$. The study area is in a typically arid continental climate, and according to the monitoring data of The Hydrogeological Team of Gansu Province, the annual mean rainfall is $129 \mathrm{~mm}$ and the annual mean evaporation is $2048 \mathrm{~mm}$. The Heihe river system originates from the Qilian mountain, and it includes two main rivers, the Heihe river and the Liyuan river. The Heihe river turns in a northwesterly direction at Zhangye city (Figure 1) and finally flows out into the downstream delta oasis at the Zhengyi gorge in the north of the study area. The annual mean runoff of the Heihe river near the south boundary of the study area where the river leaves the mountains is 1.55 billion $\mathrm{m}^{3}$, and the annual mean runoff of the Liyuan river is 0.224 billion $\mathrm{m}^{3}$. The total runoff of surface water is thus 2.38 billion $\mathrm{m}^{3}$ (data was provided by The Hydrogeological Team of Gansu, China). General groundwater flow direction is from south to north, and east to west.

The interrelation between surface water and groundwater in the region is a typical characteristic of the northwest arid region of China. In the study area, groundwater is fed by surface water seepage in the upper layers of the alluvium fans, and discharges in the form of spring flows into the Heihe river directly near the edge of fans where the sediments gradually become fine grained and hydraulic conductivity is reduced. Groundwater is also recharged by the infiltration of irrigation water. When a river incises aquifers and the river stage is lower than the groundwater

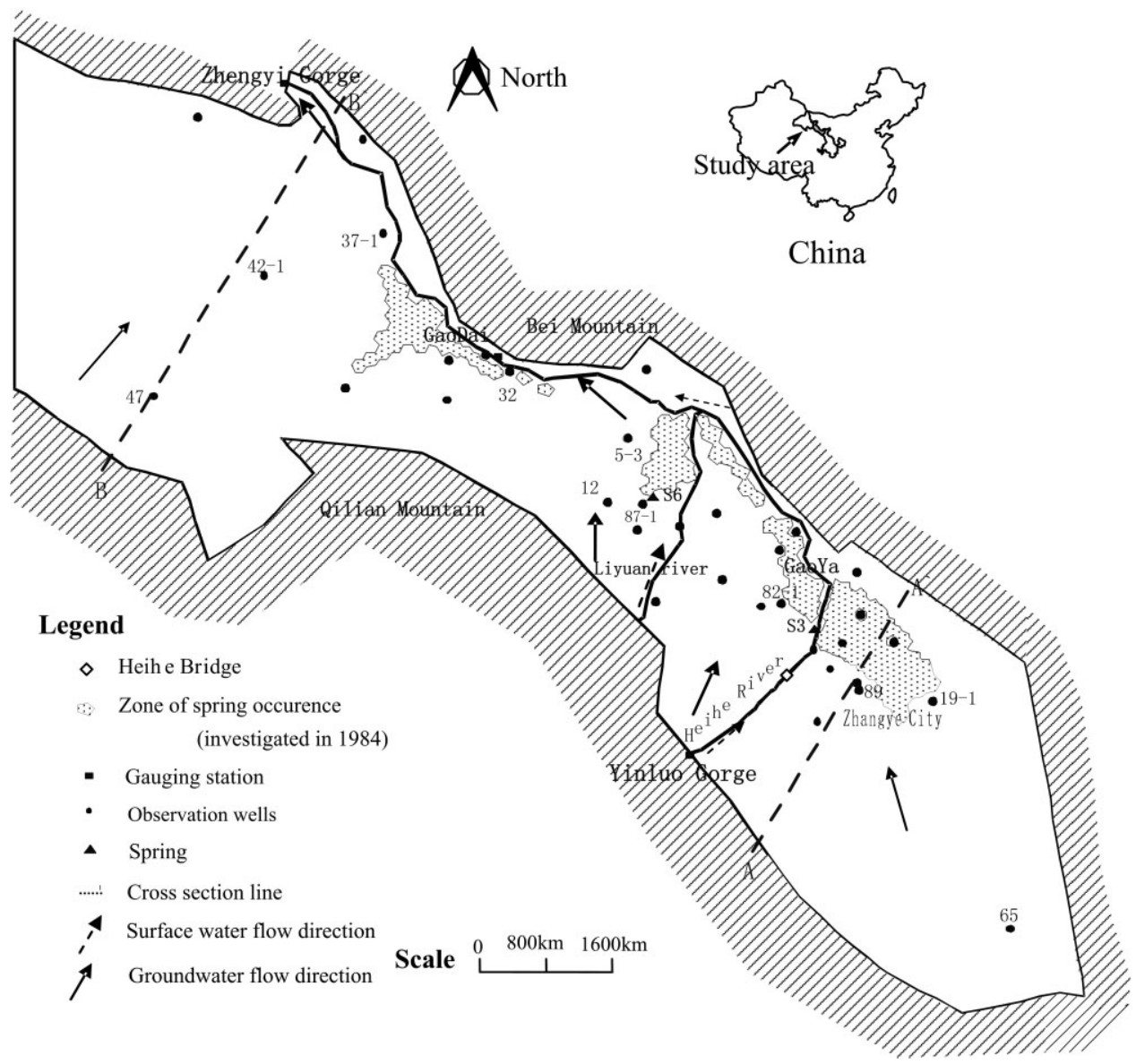

Figure 1. Location and boundary of the study area in China 
head, the river becomes a natural channel for groundwater discharge. Springs, river discharge, evaporation from shallow groundwater, and human exploitation are the main groundwater discharge components, of which, the annual mean volume of springs and river discharge amount to about $65 \%$ (data was provided by The Hydrogeological Team of Gansu, China). At the same time, the annual mean seepage from rivers, channels, and return flow of irrigation water is the main source of groundwater recharge, which accounts for $80 \%$ of the total recharge.

Since the 1950s, with the development of agriculture and industry, many reservoirs and water conveyance systems were constructed, and groundwater withdrawals increased, causing regional groundwater levels to decline in the last thirty years, especially in Zhangye city. Figure 2 shows the temporal change of groundwater level in four observation wells from 1987 to 2000. In this period, the groundwater level of well no. 19-1 (Figure 2(a)) around Zhangye city has fallen by about $10 \mathrm{~m}$. Under the influence of increased groundwater

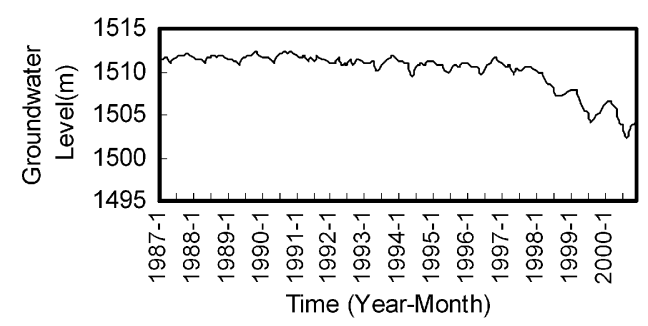

a) No.19-1

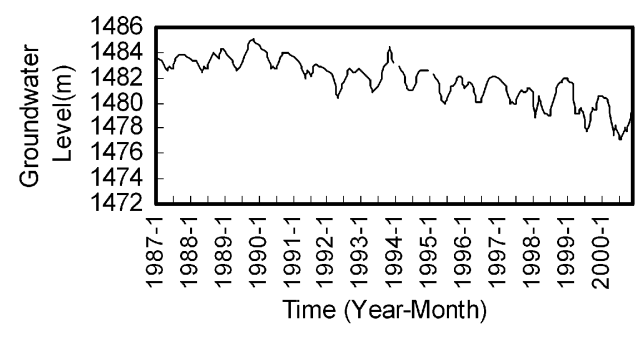

c) No.89 withdrawal around Zhangye city, groundwater levels of well no. 47 (Figure 2(b)) and 89 (Figure 2(c)) have decreased by more than $4 \mathrm{~m}$. But in the wells near the Heihe river, groundwater discharges into the river and water levels in nearby wells are largely controlled by the river stage. The seasonal fluctuation of the river stage is about $1.5 \mathrm{~m}$ and seasonal variation of groundwater levels is about $1.0 \mathrm{~m}$ (Figure 2(d)). Table I summarizes various data used in this study. More detailed geological and hydrogeological information can be found in $\mathrm{Hu}$ (2004).

\section{NUMERICAL PRESENTATION OF HYDROGELOGICAL MODEL}

\section{Model area}

The model is chosen to coincide with the area of the middle reaches of the Heihe river basin in the Hexi corridor. The southwest boundary is represented by a flux boundary, where the aquifer system is recharged by rainfall infiltration, glaciers, and snowmelt. The northeast

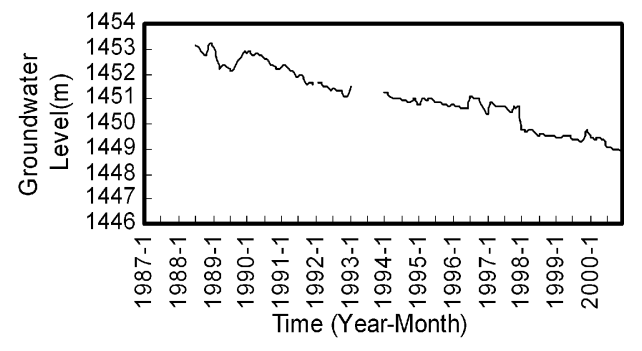

b) No.47

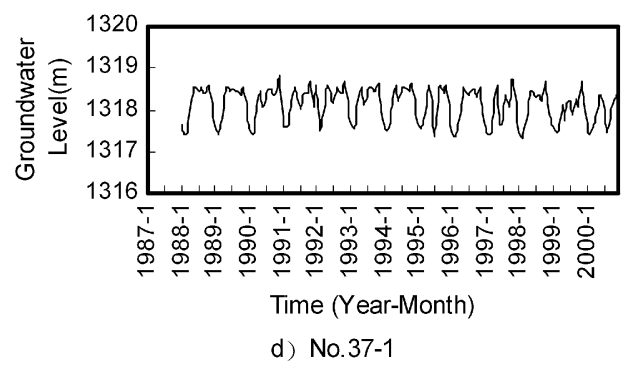

d) No.37-1

Figure 2. Change of groundwater levels over time from 1987 to 2000 in four typical monitoring wells

Table I. Data collection for model run

\begin{tabular}{ll}
\hline Items & Collected data \\
\hline Hydrogeology data & 101 boreholes drilled in 1990s; \\
& 71 wells for pumping tests; \\
& 2 wells for yield tests \\
Two typical hydrographic cross sections (previous study) & Investigated annual lateral boundary flow flux in 1984 and 2000 \\
& 34 wells: location and groundwater level at each month from 1987 to 2002 \\
Observation wells data & Groundwater level statistics from 1995 to 2000 \\
& 3 stations: rainfall and evaporation at each month from 1995 to 2000 \\
Weather data & 3 gauging station (Yinluo, GaiYa, and Zhengyi gorges): the Heihe river stage at each month from \\
Hydrological data & 1995 to 2002 investigated river runoff in December, 2002 \\
& Investigated spring flows in 1984 \\
& Flux of two springs in each month from 1984 to 2000 \\
& Annual mean river runoff data \\
& The coefficient of annual rainfall infiltration \\
Water use & Annual groundwater exploration, return flow from irrigation and channels
\end{tabular}



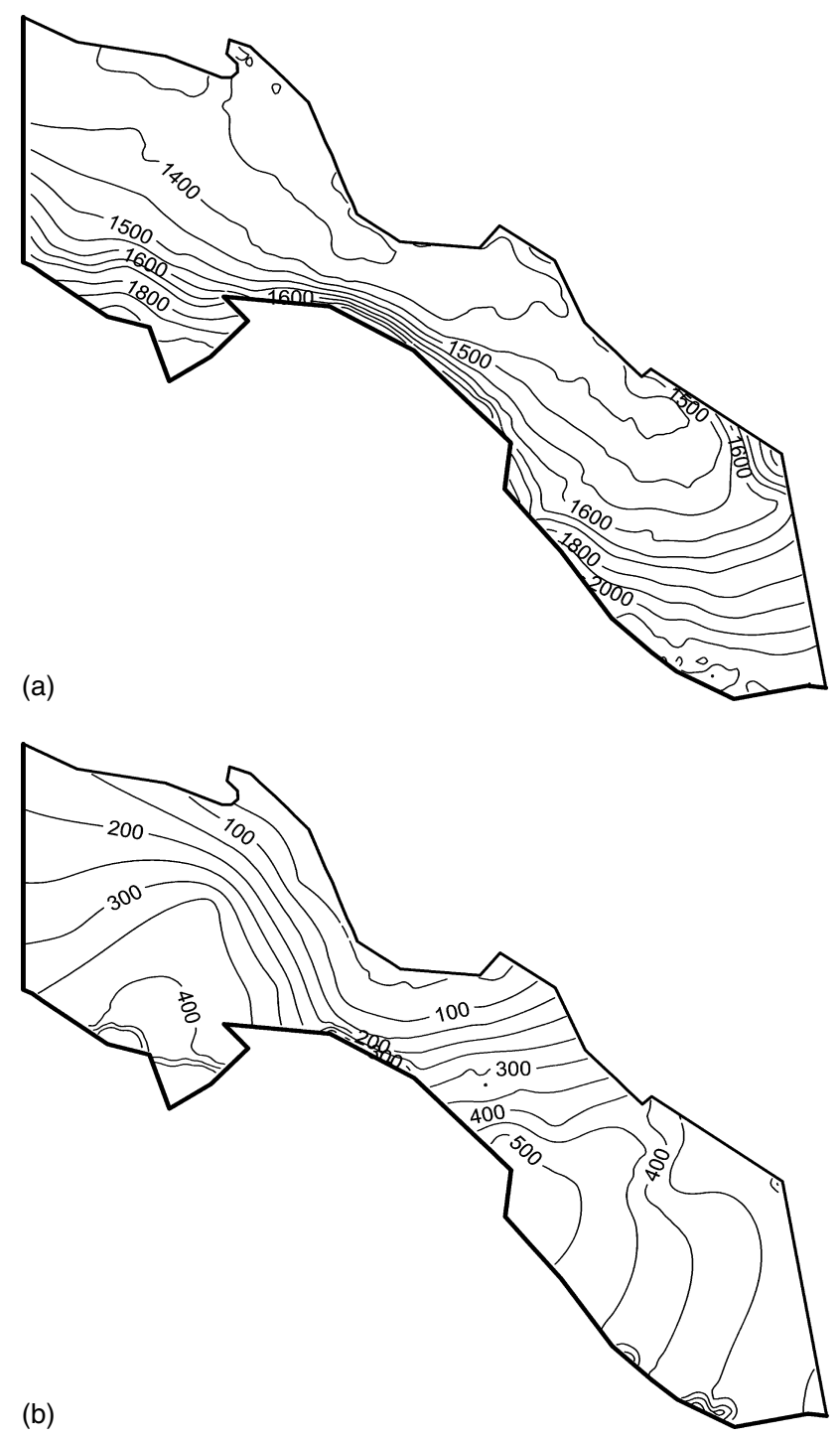

Figure 3. The contour maps of ground elevation and total aquifer thickness (a) contour map of ground elevation, (b) contour map of total thickness of aquifers

boundary is set to be a no-flow boundary. The western boundary is extended to the water divide between the Heihe river basin and the adjoining basin and is represented by a no-flow boundary. The upper boundary includes infiltration from rainfall, seepage from the Heihe river and channels, irrigation return flows in irrigated areas, discharges in the form of groundwater evaporation, and springs. The consolidated quaternary sediments $\left(Q_{1}\right)$ are treated as the bottom no-flow boundary. Figure 3 shows the contour maps of ground elevation and the total aquifer thickness. The aquifer thickness ranges from 50 to $800 \mathrm{~m}$, but in most of the area, the aquifer thickness is between 100 and $300 \mathrm{~m}$.

\section{Conceptual model}

Figure 4 shows two typical hydrogeological cross sections (marked in Figure 1) in the south and north of the study area, respectively. From Figure 4, the aquifer system is multilayered in the north part of the model, where groundwater discharges almost vertically upward into the Heihe river bed. At the same time, the Heihe river incises the shallow part of the aquifer, and the river is thus 'partially penetrating'. In the south part of the model area, the aquifer system is represented by a relatively homogeneous sandy layer of considerable thickness. The lithology can be classified into clay, loose sand with gravel, fine-grained sand, and weathered granite and they are interlaced in the northern part of the study area. The maximum number of layers of aquifers and aquitards can reach 8. Many of the wells intercept more than one aquifer and are therefore multilayered wells. All these characteristics demonstrate that vertical flow is significant in the study area, therefore, a threedimensional model is necessary to represent the flow system. Also, the groundwater level data about well 53 (Figure 1) in different layers demonstrate there are vertical differences (about $1.0 \mathrm{~m}$ ) of groundwater level. The EHC approaches presented by Chen and Jiao (1999) for simulating flows associated with multilayered wells was used in this study. In order to improve the model reliability, not only the observed groundwater levels but also the measured springs and baseflow were used as calibration targets of the numerical model.

\section{Governing equation of groundwater flow model}

The governing equation for groundwater flow is the following:

$$
\begin{aligned}
& \frac{\partial}{\partial x}\left(K_{h} \frac{\partial H}{\partial x}\right)+\frac{\partial}{\partial y}\left(K_{h} \frac{\partial H}{\partial y}\right)+\frac{\partial}{\partial z}\left(K_{z_{e}} \frac{\partial H}{\partial z}\right)-W \\
& \quad=S_{s} \frac{\partial H}{\partial t},(x, y, z) \in D, t>0
\end{aligned}
$$

The meaning of each symbol could be seen in the definition of the symbols. The initial condition is shown in the following equation.

$$
\left.H(x, y, z, t)\right|_{t=0}=H_{0}(x, y, z)
$$

The lateral boundary conditions include flow boundary and could be expressed in the Equation 3.

$$
\left.K_{n} \frac{\partial H}{\partial t}\right|_{(x, y, z) \in B_{2}}=q(x, y, z, t)
$$

Recharge includes rainfall infiltration, channel seepage, and return flow of irrigation water. Groundwater pumping is incorporated through sink terms. According to the tests of groundwater movement in the unsaturated zone, groundwater evaporation at node i $\left(Q_{e i}\right)$ could be calculated by Equation 4, where $D_{g}$ is groundwater depth, $\varepsilon_{0}$ is evaporation coefficient at surface water, and $b$ is empirical coefficient (set to 0.9858 in the model).

$$
Q_{e i}=A_{i} \cdot \varepsilon_{0} \cdot \exp \left(-b \cdot D_{g}\right)
$$

The interaction between groundwater, rivers, and springs is discussed in the following section. 

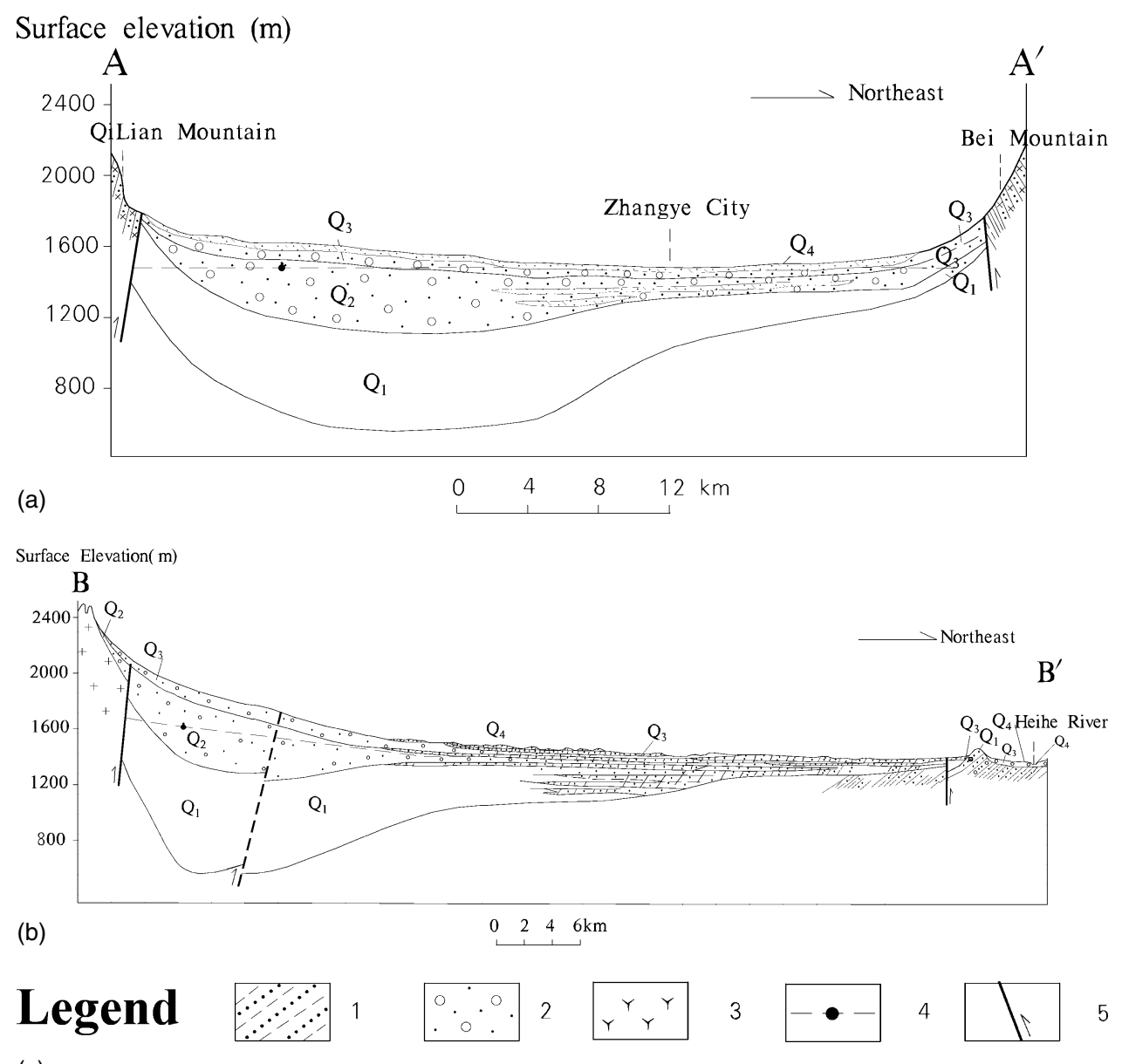

(c)

Figure 4. Hydrostratigraphy along the cross-section line (a) Along line AA, (b) Along line BB, (c)legend of hydrostratigraphy, 1: clay; 2: sand with gravel; 3: weathered granite; 4: groundwater level; 5: fault

\section{Numerical presentation of the interaction between groundwater and rivers}

The hydraulic connection between rivers and groundwater in the study area can be represented in three ways. When the groundwater table is below the base of the semipermeable riverbed, the hydraulic connection is referred to as infiltration type. In this case, unsaturated flow is involved. The model used in this paper is based on the traditional saturated groundwater flow model and
Figure 5(a) and (c) show the conceptual model of calculating the baseflow to rivers. Assume that the bottom elevation of the semipermeable layer is $Z_{s}$. The groundwater hydraulic head of this node is $H_{s}$, groundwater level of this node in the underlying layer is $H_{s+1}$, and river stage there is $H_{r}$. The vertical hydraulic conductivity of the semipermeable layer is $K_{z}$ and the thickness of the semipermeable layer is $M^{\prime}$. The interaction relation and baseflow follow from Equation 5.

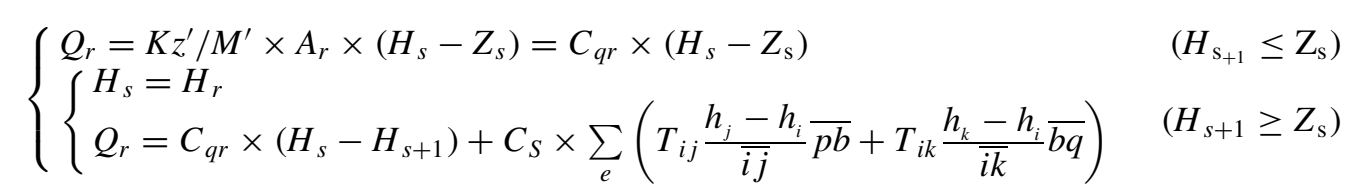

the unsaturated flow is simplified using the description of the hysteresis of river seepage (details could be seen in $\mathrm{Hu}$ et al., 2005). If no unsaturated flow develops beneath the river, the hydraulic connection between the river and groundwater is referred to as injection type. In this case, the river is similar to an injection well and a water mound is formed near the river. When groundwater level is higher than the river stage, groundwater recharges the river.

\section{Numerical presentation of spring flow}

Springs occur when the groundwater table intersects the groundwater surface. The elevation of a spring is a constraint to spring flow occurrence. If the seepage velocity at the spring is very large and groundwater flow does not follow Darcy's law, the EHC (Chen and Jiao, 1999) will replace the hydraulic conductivity. The 


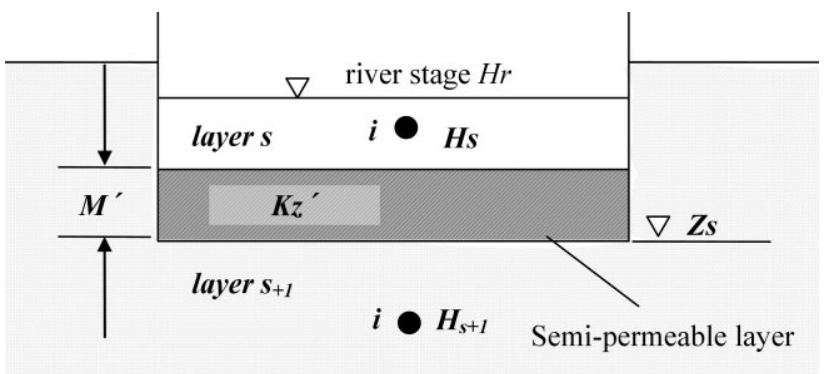

(a)

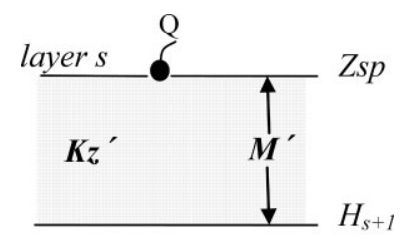

layer $s_{+1}$

(b)

Figure 5. Schematic figure of flux calculation for river and spring (a) cross section for calculating baseflow, (b) cross section for calculating spring flux, (c) plan view

equation for calculating spring flux by Darcy's law is according to Equation 6 (Figure 5(b)).

$$
=S_{s i} \frac{h_{i}^{n+1}-h_{i}^{n}}{\Delta t} A_{i} \quad(i=1,2,3 \cdots N)
$$

This equation can be rewritten as Equation 8 (details can be seen in Chen and Tang, 1994).

$$
\begin{aligned}
\sum_{e} & {\left[T_{i j} \frac{\overline{p b}}{\overline{i j}} h_{j}^{n+1}+T_{i k} \frac{\overline{b q}}{\overline{i k}} h_{k}^{n+1}\right] } \\
+ & {\left[\frac{K_{i i^{\prime}}}{Z_{i^{\prime}}-Z_{i}} h_{i^{\prime}}^{n+1}+\frac{K_{i i^{\prime \prime}}}{Z_{i}-Z_{i^{\prime \prime}}} h_{i^{\prime \prime}}^{n+1}\right] A_{i} } \\
- & {\left[\sum_{e}\left(T_{i j} \frac{\overline{p b}}{\overline{i j}}+T_{i k} \frac{\overline{b q}}{\overline{i k}}\right)+\left(\frac{K_{i i^{\prime}}}{Z_{i^{\prime}}-Z_{i}}+\frac{K_{i i^{\prime \prime}}}{Z_{i}-Z_{i}^{\prime \prime}}\right)\right.} \\
& \left.\times A_{i}+S_{s i} \frac{A_{i}}{\Delta t}\right] h_{i}^{n+1}=-S_{s i} \frac{h_{i}^{n}}{\Delta t} A_{i}-Q_{w i}
\end{aligned}
$$

This equation is solved using the successive overrelaxation method and the acceleration relaxation factor is generally between 1.0 and 2.0 .

\section{DATA PREPARATION}

To better represent the rapid changes in groundwater levels near pumping wells, the grid elements are

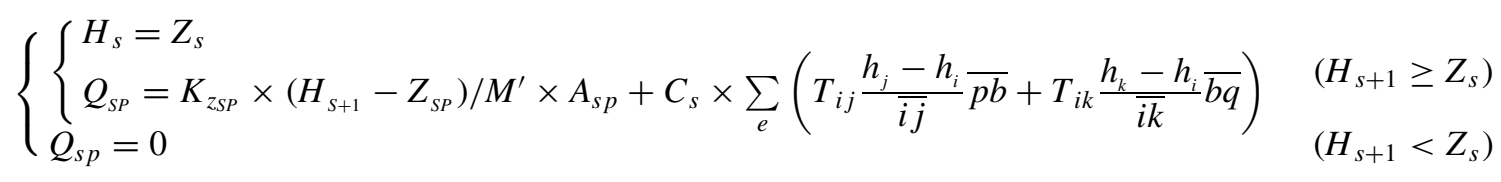

In the study area, only two springs (nos S3 and S6) are monitored from 1984, and many other springs with small flux were not investigated in detail. However, the scope and flux of springs were investigated in 1984, and so the areas of spring outlets were determined. Each spring outlet is included into one node, and the total spring flux is formulated by the sum of the flux of each spring node.

\section{Finite difference method with random polygon grids}

The modeled area was fragmented into a series of hexahedral or wedge-shaped elements and a triangular mesh in an assistant network (Figure 6(a)). When considering the water balance zone around grid i (Figure 6(b)), according to Darcy's law and the continuity concept, the change in groundwater storage at node $\mathrm{i}$ could be the sum of lateral and vertical flows, and groundwater sources and sinks (such as pumping rate, spring flux, discharge to rivers, river seepage, rainfall infiltration, etc.). The water balance equation around grid $i$ is expressed by Equation 7 .

$$
\begin{aligned}
& \sum_{e}\left[T_{i j} \frac{h_{j}^{n+1}-h_{i}^{n+1}}{\overline{i j}} \overline{p b}+T_{i k} \frac{h_{k}^{n+1}-h_{i}^{n+1}}{\overline{i k}} \overline{b q}\right] \\
& \quad+K_{i i^{\prime}} \frac{h_{i}^{\prime n+1}-h_{i}^{n+1}}{Z_{i}^{\prime}-Z_{i}} A_{i}-K_{i i^{\prime \prime}} \frac{h_{i}^{n+1}-h_{i^{\prime \prime}}^{n+1}}{Z_{i}-Z_{i^{\prime \prime}}} A_{i}+Q_{w i}
\end{aligned}
$$

progressively finer toward these wells. The simulation period is from January 1995 to December 2000. The time step is one month owing to the degree of collected data and there are 72 time steps in total. Considering the properties of lithology, a model layer is determined to 8 . Details of the mesh system are shown in Figure 7(a) and one cross section of the model along line 12 is shown in Figure 7(b). Each layer is represented by 1973 nodes and 3775 elements. The entire model of 8 layers thus has 15784 nodes and 30040 elements. The total area of the model is approximately $8716 \mathrm{~km}^{2}$.

Many aquifer parameters are involved, owing to the complexity of the aquifer system. These parameters include horizontal and vertical hydraulic conductivities $\left(K_{h}\right.$ and $\left.K_{z}\right)$, storativities $\left(S_{s}\right)$, and specific yields $\left(S_{y}\right)$. The zones are based entirely on the topographical location, geology, and soil and rock types. An initial assessment and its possible range for each of the parameters is obtained based on the various geologic and hydrogeologic reports, pumping-test data and other literature from previous studies. Both the trial-and-error method and the Fibonacci optimization method (Chen and Tang, 1994) were used to calibrate the model against observed data to achieve the smallest possible objection function which is defined as the sum of the squares of the differences between the observed and calculated results, including 


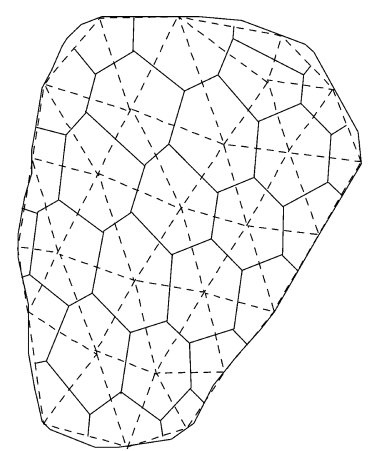

(a)

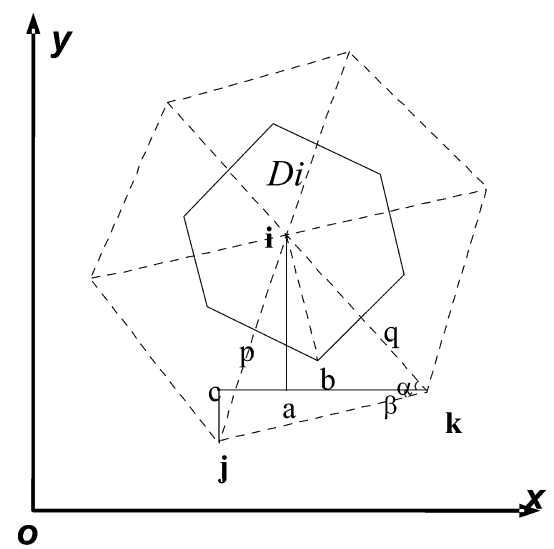

(b)

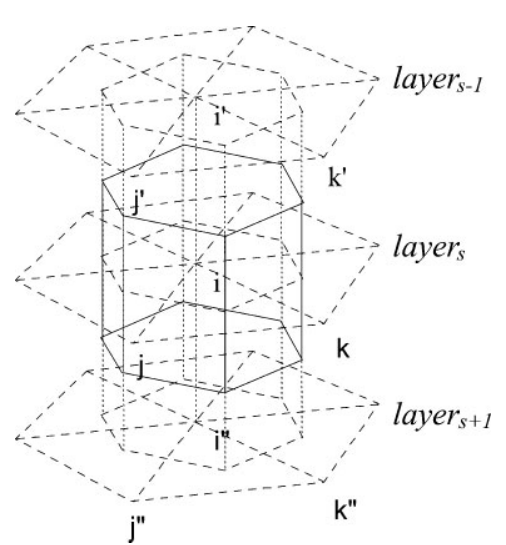

(c)

Figure 6. Schematic figure for water balance analysis of polygon-grid mesh

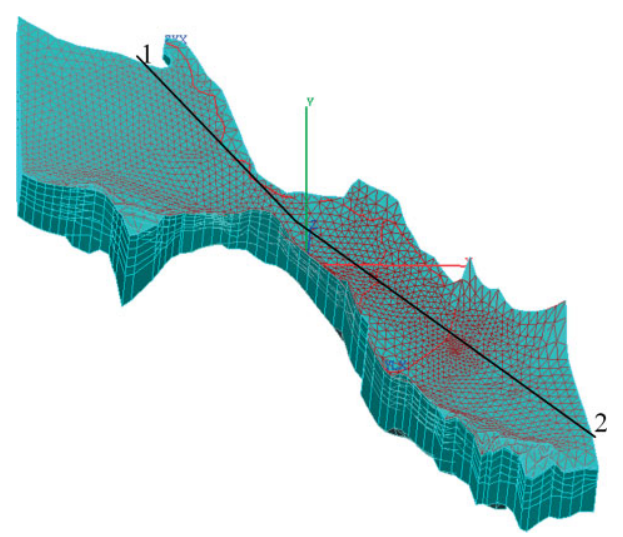

(a)

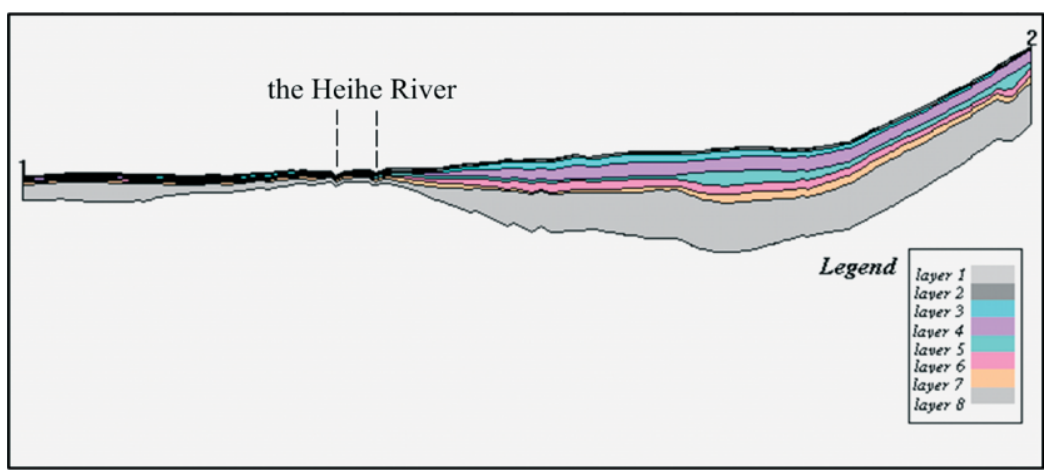

(b)

Figure 7. 3D view of model discretization : (a) 3D mesh view, (b) cross section of model along line 12

both water level and spring flux. Calibrated parameter zoning of the study area is shown in Figure 8 and values are shown in Table II.

\section{MODEL RESULTS AND DISCUSSION}

\section{Comparison between simulated and observed results}

Six typical observation wells were chosen from among the 34 wells for comparison between the observed and simulated heads (Figure 9(a-f)). At the same time, the observed discharges from two monitored springs were also used as calibration targets (Figure 9(g) and (h)). Overall, the matches between the observed and calculated heads and spring flux are reasonable. This shows that the model can simulate the dynamic process of the hydrogeological system.

To provide information on the overall match between the observed and simulated water levels in all the monitoring wells, Table III presents some statistics concerning the absolute errors in the simulated water levels, and Figure 10 presents some statistics about the contrast of simulated and observed water levels. This figure shows that the relative error, which is defined as the absolute difference between the simulated water level and the observed water level divided by the observed water level, is between a relative error of $(+5 \%$ and $-5 \%)$. A reasonably good match between the observed and simulated water levels can also be seen from the statistics in Table III. The errors in simulated water levels in over $80 \%$ of the wells are less than $1 \mathrm{~m}$. About $56 \%$ of the wells have errors less than $0.5 \mathrm{~m}$. The mean error of simulated groundwater values is $0.76 \mathrm{~m}$ and the root mean square error is 1.28. However, the observed heads in some wells show much greater fluctuations than those of the calculated heads, as in the case of well no. 371. This poor match may be caused by the fact that, due to a lack of detailed monthly data in some places, only the average values of groundwater withdrawal and seepage quantities of channels and irrigated region were input to the model. For the two springs, the long-term trends preserve well, but the observed spring flux shows larger fluctuations than the simulated one.

Seasonal variation of river stage, groundwater level and their interrelationship

The analysis of the relationship between rivers and groundwater leads to a better understanding of the movement of groundwater. Figure 11(a-c) shows seasonal variation of the Heihe river stages at three hydrology gauging stations from 1995 to 2000. At Yinluo gorge, the river stage reaches maximum values from June to August 


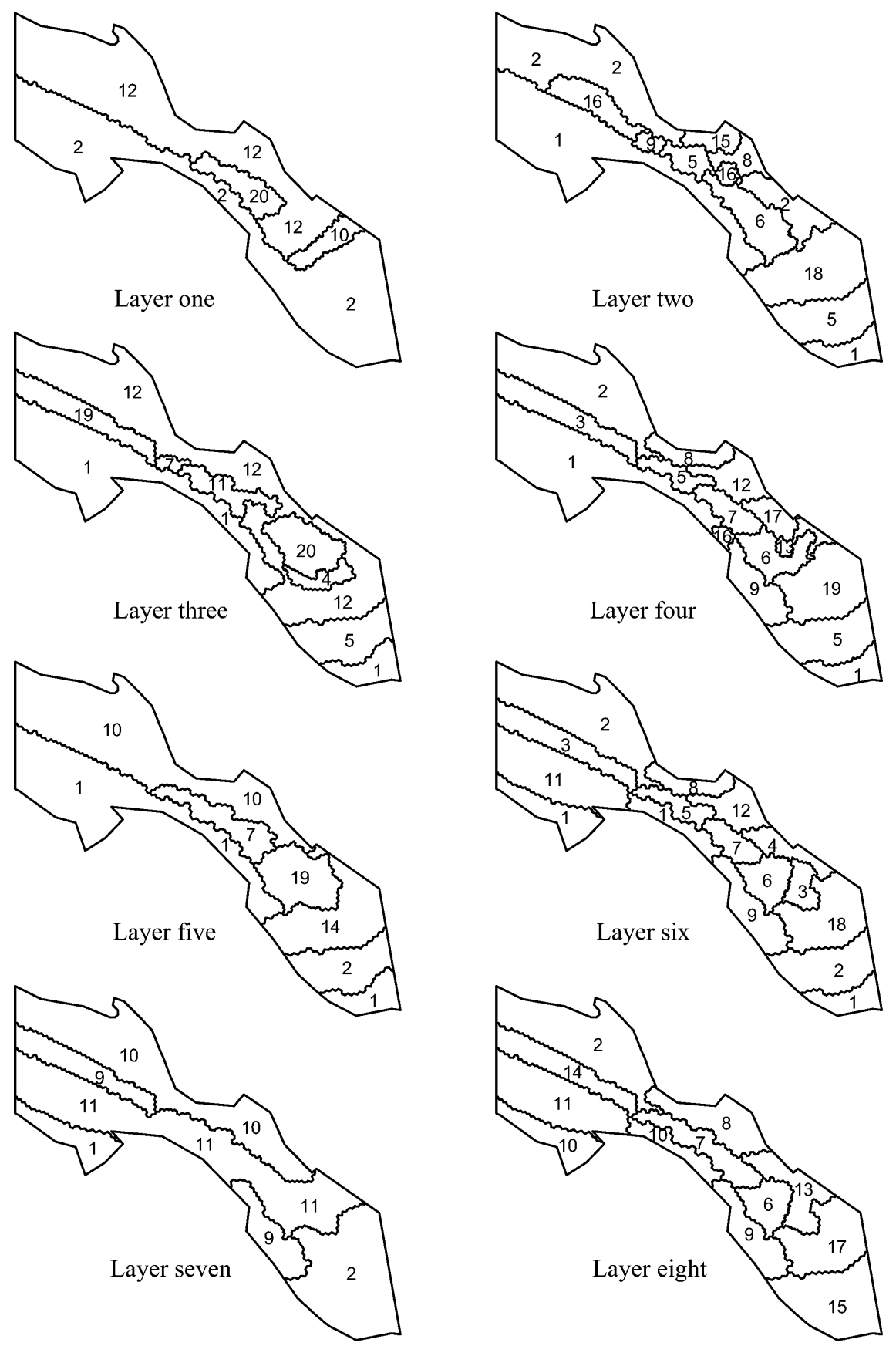

Figure 8. Parameter zonation of the study area

Table II. Parameter zones and estimated parameters

\begin{tabular}{|c|c|c|c|c|c|c|c|c|c|c|}
\hline \multirow{2}{*}{$\begin{array}{l}\text { Zones } \\
\text { Parameters }\end{array}$} & 1 & 2 & 3 & 4 & 5 & 6 & 7 & 8 & 9 & 10 \\
\hline & 11 & 12 & 13 & 14 & 15 & 16 & 17 & 18 & 19 & 20 \\
\hline \multirow[t]{2}{*}{$\mathrm{K}_{h}\left(\mathrm{~m} \mathrm{day}^{-1}\right)$} & $24 \cdot 75$ & $10 \cdot 17$ & $21 \cdot 13$ & $43 \cdot 75$ & $18 \cdot 00$ & 39.00 & 0.0083 & $0 \cdot 50$ & 4.95 & $5 \cdot 500$ \\
\hline & $0 \cdot 83$ & $27 \cdot 46$ & $4 \cdot 88$ & $12 \cdot 38$ & $0 \cdot 19$ & $0 \cdot 044$ & $2 \cdot 85$ & $22 \cdot 55$ & $38 \cdot 00$ & $0 \cdot 011$ \\
\hline \multirow[t]{2}{*}{$\mathrm{Kz}\left(\mathrm{m} \mathrm{day}^{-1}\right)$} & $6 \cdot 60$ & 1.45 & $4 \cdot 73$ & $8 \cdot 25$ & $3 \cdot 70$ & $7 \cdot 70$ & 0.002 & $0 \cdot 10$ & 1.05 & $1 \cdot 100$ \\
\hline & $0 \cdot 18$ & $6 \cdot 71$ & $0 \cdot 88$ & $3 \cdot 30$ & 0.036 & 0.0098 & 0.66 & 4.40 & 11.00 & $0 \cdot 0017$ \\
\hline \multirow[t]{2}{*}{ Sy } & $0 \cdot 30$ & $0 \cdot 25$ & $0 \cdot 26$ & $0 \cdot 30$ & $0 \cdot 22$ & $0 \cdot 30$ & 0.05 & $0 \cdot 10$ & $0 \cdot 18$ & $0 \cdot 14$ \\
\hline & $0 \cdot 11$ & $0 \cdot 30$ & $0 \cdot 15$ & $0 \cdot 20$ & $0 \cdot 05$ & $0 \cdot 05$ & - & $0 \cdot 25$ & - & $0 \cdot 05$ \\
\hline \multirow[t]{2}{*}{ Ss $\left(\times 10^{-6}\right)\left(\mathrm{m}^{-1}\right)$} & $5 \cdot 00$ & $8 \cdot 00$ & $7 \cdot 00$ & $3 \cdot 00$ & $8 \cdot 00$ & $4 \cdot 50$ & $35 \cdot 00$ & $12 \cdot 00$ & $10 \cdot 00$ & $10 \cdot 00$ \\
\hline & $12 \cdot 00$ & $4 \cdot 50$ & - & 8.00 & $20 \cdot 00$ & $30 \cdot 00$ & $10 \cdot 00$ & $5 \cdot 50$ & $3 \cdot 50$ & $25 \cdot 00$ \\
\hline
\end{tabular}



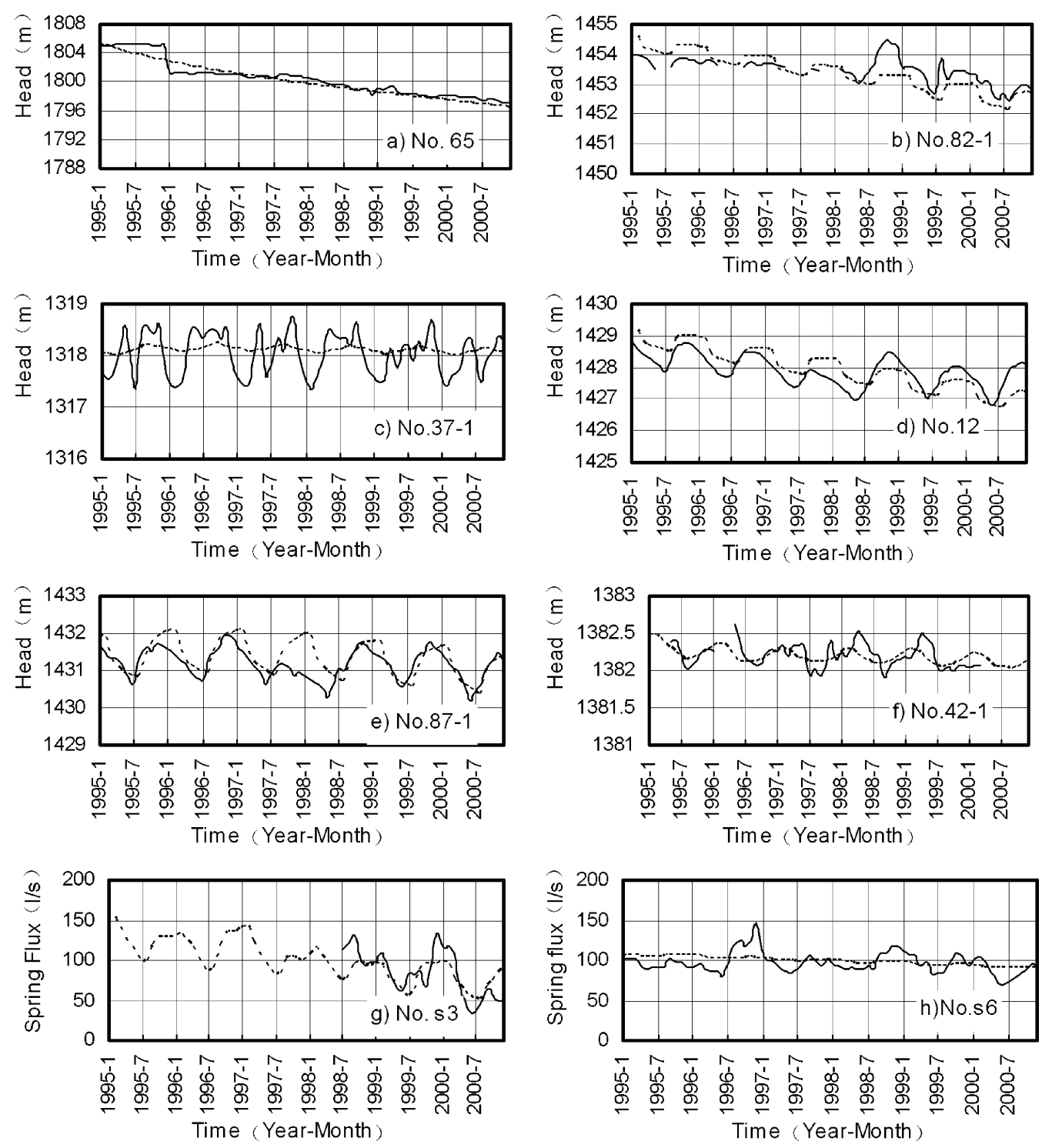

Figure 9. Comparison between observed (solid lines) and simulated (dotted lines) water levels in six observation wells (a-f) and spring flux of two springs $(\mathrm{g}-\mathrm{h})$

Table III. Statistics of the absolute errors in simulated groundwater level

\begin{tabular}{lccccrr}
\hline Errors $(m)$ & $\Delta \mathrm{H} \leq 0.2$ & $0.2<\Delta \mathrm{H} \leq 0.5$ & $0.5<\Delta \mathrm{H} \leq 1.0$ & $1.0<\Delta \mathrm{H} \leq 1.2$ & $>1.2$ & Total \\
\hline No. of readings & 589 & 727 & 560 & 109 & 324 & 2309 \\
Percentage (\%) & 25.51 & 31.49 & 24.25 & 4.72 & 14.03 & 100 \\
\hline
\end{tabular}

each year, but at Zhengyi gorge, the river stage has minimum values during this period. At Gaoya, the river stage remains almost at the same level but with small variations. In the upper part of the middle reaches of the Heihe river, the river recharges the groundwater, so that the river stage varies mainly in response to weather conditions. However, groundwater level is generally higher than the river stages in the lower part, which means the Heihe river becomes the channel for groundwater discharge, and groundwater level is controlled by the river stages. In the middle part, the groundwater level is higher than the river stages in some regions but lower than the river stages in others. Is there any obvious interface where the groundwater is transferred from the gaining system (the decoupling state) to the losing system (the coupling state)? The simulated results showed that the area around the Heihe Bridge is one such key point, and the actual location is affected by the seasonal variations in the river stages and groundwater extraction for irrigation.

\section{Temporal change of groundwater discharge to rivers and springs}

Figures 12 and 13 show the changes of simulated groundwater baseflow to rivers and springs. The simulated groundwater discharge to the Heihe river fluctuates considerably in a year and decreases slightly 


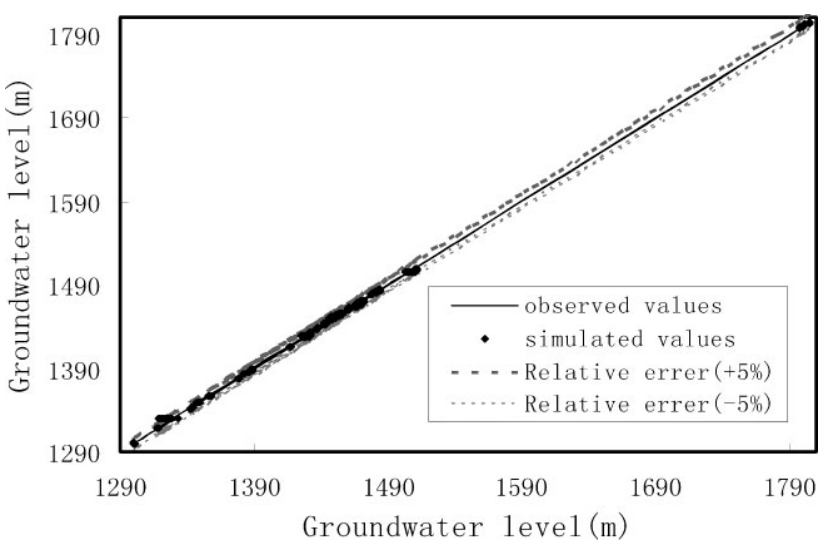

Figure 10. Comparison between observed and simulated groundwater levels
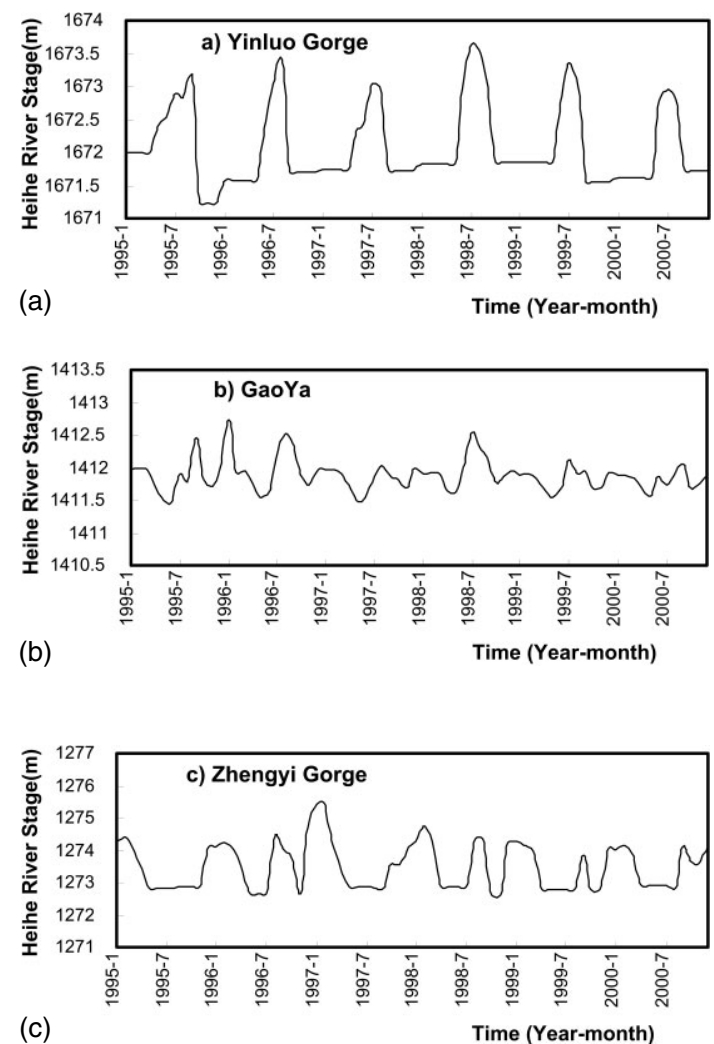

Figure 11. Temporal variation of the Heihe river stage from 1995 to 2000

year by year. The spring discharge varies much less, but decreases noticeably over a period of time. This is because the spring discharge is largely affected by the amount of groundwater exploitation, which does not fluctuate much seasonally, but increases steadily with time.

The Heihe river runoff at several reaches from the Heihe bridge to Zhengyi gorge in December 2002, was measured and shown as the solid line in Figure 14. As there is limited usage of water in December, and springs almost join into rivers, the change of river flux in December can represent the change of groundwater discharge to the river and springs. Although the time of measurement is beyond the model simulation period, the data provides a good opportunity to verify the model.

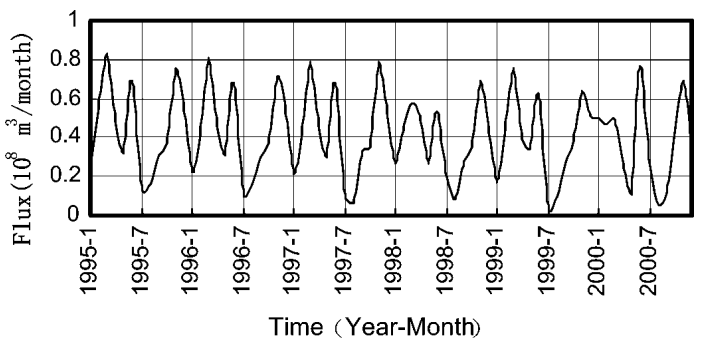

Figure 12. Change of simulated groundwater discharge to the Heihe River with time

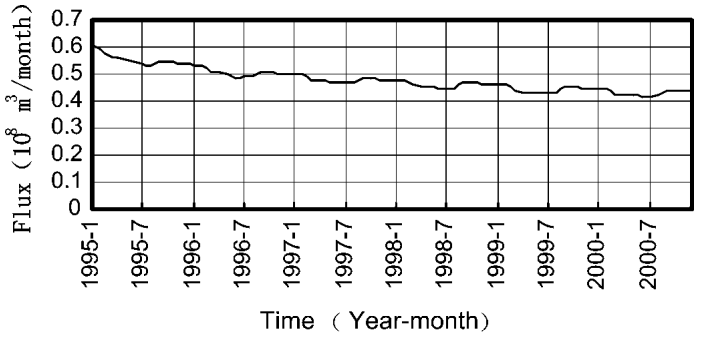

Figure 13. Change of simulated groundwater discharge to springs with time

The model is run to predict groundwater discharge to rivers at the same reaches of the Heihe river with data modification of water use for the next two years. The cumulative simulated groundwater discharge to rivers and springs is presented as a dotted line in Figure 14. The simulated groundwater discharge is greater than the measured one. This is due to two reasons: one is that the model assumed the spring flows converged into the Heihe river in December and attributed the spring flows to flux measured mostly according to the flow direction; the other is that there may exist some error in the investigation. But the model's calibration which is based on observed data between 1995 and 2000, can provide prediction for long time trends of groundwater discharge to rivers and springs in 2002. The simulation also suggests that there is a decoupling state (meaning that the relation between river and groundwater changed from the continuous state to the discontinuous state) at a reach of the Heihe river because cumulative simulated values started decreasing about $80 \mathrm{~km}$ from the Heihe bridge.

\section{Water balance analysis}

The Hydrogeological Team of Gansu Province conducted a water resource analysis in the research area in 1984. The main groundwater recharge sources were rivers, channel seepage, and return flows of irrigation water, which contribute about $83 \%$ of the total recharge. The amount of rainfall infiltration is low at only $3.5 \%$ of the total recharge. The main groundwater discharge components are derived from rivers, springs, groundwater evaporation, and groundwater abstraction, which contribute $30,34,21$, and $15 \%$ respectively, of the total discharge. The discharges to rivers and springs are the key components $(64 \%)$ of the total groundwater discharge. 


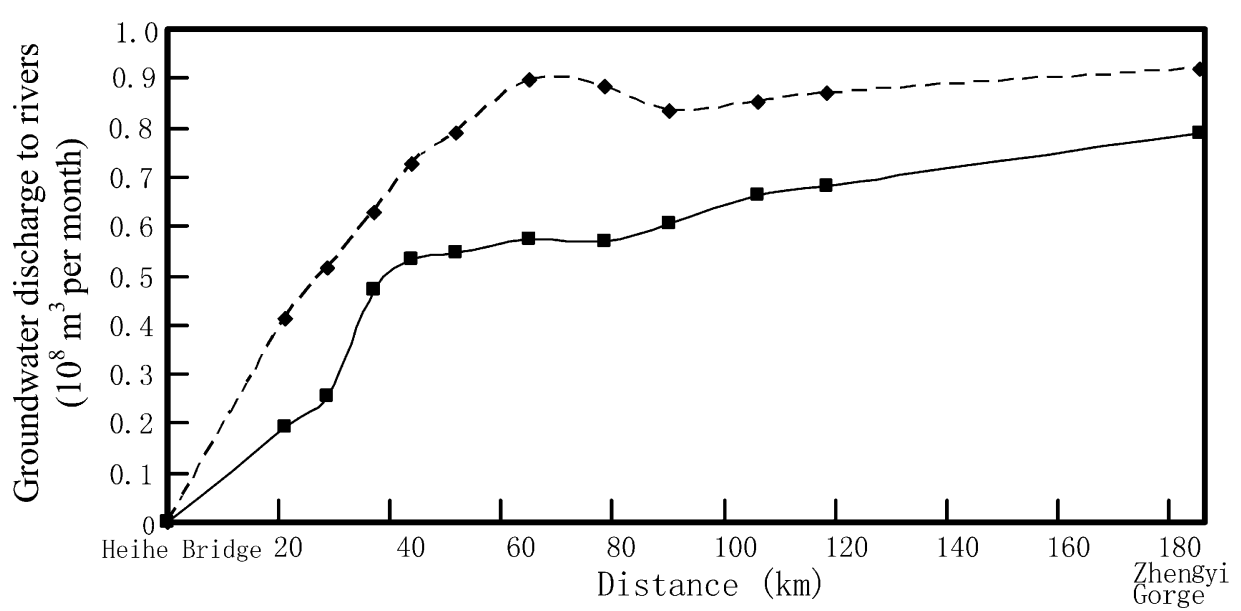

Figure 14. Comparison of predicted (dotted line) and measured (solid line) cumulative groundwater discharge amount along the Heihe river in December 2002

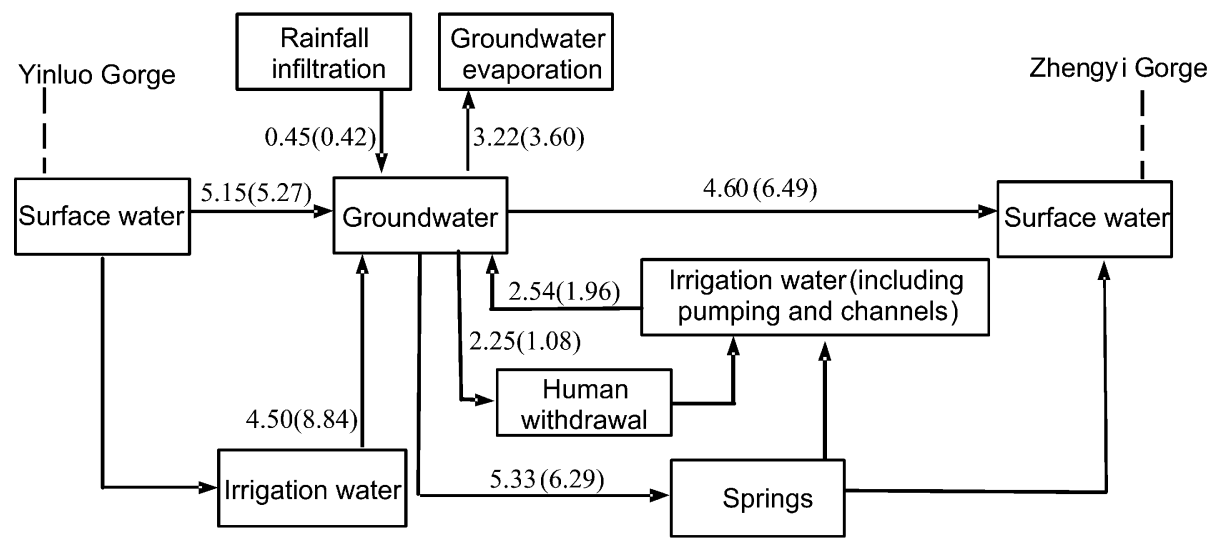

Figure 15. Comparison of components of water budget from the model and those estimated by The Hydrogeological Team of Gansu Province (in brackets), reference year 1984. The simulated values are annual mean values from 1995 to 2000 . (Unit: $10^{8} \mathrm{~m}^{3}$ per year)

Figure 15 shows values of the various components of water budget in this area calculated from the numerical model and those reported by The Hydrogeological Team (shown in brackets). The calculated values are the average values from January 1995 to December 2000. Overall, the calculated values and the estimates for 1984, agree reasonably well, except for a few components which show some obvious changes from the 1980 s to the 1990s. For example, the groundwater baseflow to rivers reduces from $6.49 \times 10^{8} \mathrm{~m}^{3}$ to $4.60 \times 10^{8} \mathrm{~m}^{3}$; the irrigation water return to groundwater changes from $8.84 \times 10^{8} \mathrm{~m}^{3}$ to $4.50 \times 10^{8} \mathrm{~m}^{3}$, and the groundwater withdrawal increases from $1.08 \times 10^{8} \mathrm{~m}^{3}$ to $2.25 \times 10^{8} \mathrm{~m}^{3}$.

\section{CONCLUSIONS}

The geology and hydrogeology in the middle reaches of the Heihe river basin were investigated to understand the hydrostratigraphy of the aquifer system. A three-dimensional numerical model which characterized groundwater interaction with rivers and springs was developed to investigate the dynamic interaction between them. By calibrating the model against both the observed groundwater levels and the baseflow to rivers and spring flows, the aquifer parameters of the system were estimated. The model outputs fit reasonably well with the observed results, which indicate that the numerical model can reproduce the dynamic processes in both groundwater and surface water systems, as well as their interaction over the simulation period.

The model was also run to predict the river flux in the reaches between the Heihe bridge and Zhengyi gorge for 2002, which matches reasonably well with the observed value. The water balance was analysed using the model results and compared with the results obtained by previous researchers. The study also shows that groundwater discharge to rivers and springs has decreased year after year owing to the impact of human activities. Decline of groundwater levels will lead to a decrease in baseflow to rivers and spring discharge. This study also indicates that the relationship between groundwater and rivers has varied from coupling to decoupling at some reaches, which helps to clarify the dynamic processes of the groundwater system. However, due to the vast size of the study area and the lack of detailed data, rivers have been included as linear features and the model did not take account of the effect of river width. The mechanism of the transition process from the coupling to the decoupling state is not 
discussed in this research, and will require further work. For sustainable development of this area, groundwater and surface water must be used rationally, and the local government should take measures to reduce groundwater abstraction for agricultural purposes by improving the efficiency of irrigation water usage.

\section{ACKNOWLEDGEMENTS}

This research was supported by the National Nature Science Foundation of China (Grant number: 50509012 and 40235053). The authors also express their thanks to The Hydrogeoglogical Team and Hydrology and Water Resources Units of Zhangye in Gansu Province, China, which provided information including site hydrogeology and groundwater and river data, and two anonymous reviewers for their comments that were helpful in revising this manuscript.

\section{DEFINITION OF SYMBOLS:}

$A_{i}=$ The area controlled by node $\mathrm{i}\left(\mathrm{L}^{2}\right)$;

$A_{r}=$ The area controlled by river node $\left(\mathrm{L}^{2}\right)$;

$A_{s p}=$ The area controlled by spring node $\left(\mathrm{L}^{2}\right)$;

$b=$ Empirical coefficient used in the calculation of groundwater evaporation;

$B_{2}=$ Flux boundary;

$C_{q r}=$ Flux coefficient and is the product of the coefficient $\left(\varepsilon=K_{z}^{\prime} \frac{H_{r}-H_{s}}{M^{\prime}}\right)$ and $A_{r}\left(\mathrm{~L}^{2} / \mathrm{T}\right)$;

$C_{s}=$ The coefficient of the river (spring) area and river (spring) area represented in the model;

$D=$ The domain of study area;

$D_{g}=$ Groundwater depth at node i (L);

$e=$ The area based on which the water balance equation in (1) is written $(e$ could be seen in $D_{i}$ in Figure 6(b));

$H=$ The hydraulic heads (L);

$H_{0}=$ Initial hydraulic heads (L);

$h_{i}, h_{j}, h_{k}=$ Groundwater head of node $i, j, k$, respectively, (L) at layer s;

$h_{i^{\prime}}, h_{i^{\prime \prime}}=$ Head of node I at upper layer (s-1) and down layer (s+1) (L);

$H_{r}=$ River stage $(\mathrm{L})$;

$H_{s}, H_{s+1}=$ Head of node $\mathrm{i}$ at layer s and $\mathrm{s}+1(\mathrm{~L})$;

$h_{p}^{n+1}, h_{p}^{n}=$ Head of node $\mathrm{P}(P=i, j, k)$ at time $n+1$ and $n(\mathrm{~L})$;

$M^{\prime}=$ The thickness of the semipermeable layer (L);

$N=$ Numbers of nodes in discretized mesh;

$T_{i j}, T_{i k}=$ The mean transmissivity of line $i j$ and $i k\left(\mathrm{~L}^{2} / \mathrm{T}\right)$;

$\overline{i j}, \overline{p b}, \overline{i k}, \overline{b q}=$ The length of lines $i j, p b, i k, b q$, respectively (L);

$K_{h}=$ The horizontal hydraulic conductivity $(\mathrm{L} / \mathrm{T})$;
$K_{i i^{\prime}}=$ Vertical hydraulic conductivity at node i at layer s-1 (L/T);

$K_{i i^{\prime \prime}}=$ Vertical hydraulic conductivity at node i at layer $\mathrm{s}+1(\mathrm{~L} / \mathrm{T})$;

$K_{n}=$ Hydraulic conductivity at the flux boundary $(\mathrm{L} / \mathrm{T})$;

$K_{z}=$ Vertical hydraulic conductivity $(\mathrm{L} / \mathrm{T})$;

$K_{z^{\prime}}=$ Vertical hydraulic conductivity of semipermeable layer $(\mathrm{L} / \mathrm{T})$;

$K_{z e}=$ Equivalent hydraulic conductivity in the vertical direction $(\mathrm{L} / \mathrm{T})$;

$K z_{S P}=$ Vertical hydraulic conductivity of the material around a spring $(\mathrm{L} / \mathrm{T})$;

$q=$ Flow velocity of the prescribed flux boundary (L/T);

$Q_{e i}=$ Groundwater evaporation at node i $\left(\mathrm{L}^{3} / \mathrm{T}\right)$;

$Q_{r}=$ Baseflow between groundwater and surface water. If $Q_{r}>0$, groundwater recharges from rivers, otherwise groundwater discharges into the rivers $\left(\mathrm{L}^{3} / \mathrm{T}\right)$.

$Q_{s p}=$ Spring flux $\left(\mathrm{L}^{3} / \mathrm{T}\right) ;$

$Q_{w i}=$ Pumping rate of node $\mathrm{i}\left(\mathrm{L}^{3} / \mathrm{T}\right)$;

$S_{s}=$ Storativities $(1 / \mathrm{L})$;

$S_{s i}=$ Storativities of node i;

$S_{y}=$ The specific yield of the unconfined layer;

$t=$ Run time of the model (T);

$W=$ The volumetric flux per unit and representative sources and sink of water $(1 / \mathrm{T})$;

$x, y, z=$ The coordinates at the directions $\mathrm{x}, \mathrm{y}$, and $\mathrm{z}$ respectively;

$Z_{i}, Z_{i^{\prime}}, Z_{i^{\prime \prime}}=$ Elevation of node $\mathrm{i}$ at layer $\mathrm{s}$, upper layer, and down layer $(\mathrm{L})$;

$Z_{S}=$ Bottom elevation of semipermeable layer (L);

$Z_{S P}=$ Elevation of the spring outlet (L);

$\Delta t=$ Time step of the model (T);

$\varepsilon_{0}=$ Evaporation coefficient at surface water.

Explanation: If node $i$ is river node, $A$ is $A_{r}$, else if node $i$ is spring node, $A$ is $A_{s p}$

\section{REFERENCES}

Angelini P, Dragoni W. 1997. The problem of modeling Limestone springs: the case of Bagnara (north Apennines, Italy). Ground Water 35(4): $612-618$

Atkinson TC. 1977. Diffuse flow and conduit flow in limestone terrain in Mendip Hills, Somerset (Great Britain). Journal of Hydrology 35: 93-110.

Bhar AK, Mishra GC. 1997. One-dimensional spring flow model for time variant recharge. Hydrological Sciences Journal 42(3): 381-390.

Carol MW, John AH. 2000. Prediction of the quality and quantity of Maramec Spring Water. Ground Water 38(2): 218-225.

Chen CX. 1995. Groundwater flow model and simulation method in triple media of Karstic tube-fissure-pore. Journal of China University of Geosciences 20(4): 361-366, (in Chinese).

Chen CX, Tang ZH. 1994. Numerical Methods of Groundwater Flow Problem. China University of Geosciences Publishing House: Wuhan, (in Chinese).

Chen CX, Jiao JJ. 1999. Numerical simulation of pumping test in multilayer wells with non-Darcian flow in the wellbore. Ground Water 37(3): 465-474. 
Eldin MEHA, Ahmed MS, Rao VVSG, Dhar RL. 2000. Aquifer modelling of the Ganga-Mahawa sub-basin, a part of the Central Ganga Plain, Utter Pradesh, India. Hydrological Processes 14(2): 297-315.

Grapes TR, Bradley C, Petts GE. 2005. Dynamics of river-aquifer interactions along a chalk stream: the River Lambourn, UK. Hydrological Processes 19(10): 2035-2053.

Hamada H. 1999. Analysis of the interaction between surface water and groundwater using Radon-222. Jarq-Japan Agricultural Research Quarterly 33(4): 261-265.

Hu LT. 2004. Researches and case study on three-dimensional polygon finite different groundwater flow modeling software development (In Chinese). $\mathrm{PhD}$ thesis, China University of Geosciences, Wuhan, China.

Hu LT, Chen CX, Wang ZJ. 2005. Numerical simulation methods for stream and aquifer interaction. Proceedings of International Symposium on Sustainable Water Resources Management and Oasis-hydrospheredesert Interaction in Arid Regions. Tsinghua University Press: Beijing, China; 198-205.

Hunt R. 2003. Ground water-lake interaction modeling using the LAK3 package for MODFLOW 2000, Ground Water 41(2): 114-118.

Hunt RJ, Steuer JJ, Mansor MTC, Bullen TD. 2001. Delineating a recharge area for a spring using numerical modeling, Monte Carlo techniques, and geochemical investigation. Ground Water 39(5): $702-712$.
Jian WB, Yao H, Wen XH, Chen BR. 1998. A nonlinear time series model for spring flow: an example from Shanxi Province, China. Ground Water 36(1): 147-150.

Negrel P, Peter-Giraud E, Barbier J, Gautier E. 2003. Surface water-groundwater interactions in an alluvial plain: chemical and isotopic systematics. Journal of Hydrology 277: 248-267.

Rushton KR. 2003. Groundwater Hydrology: Conceptual and Computational Models. John Wiley and Sons: USA, 415, ISBN:0-470-85004-3.

Sear DA, Armitage PD, Dawson FH. 1999. Groundwater dominated rivers. Hydrological Processes 13(3): 255-276.

Sophocleous M. 2002. Interactions between groundwater and surface water: the state of the science. Hydrological Journal 10(1): 52-67.

Swain ED, Wexler EJ. 1996. A Coupled Surface-water and Groundwater Flow Model (MODBRNCH) for Simulation of Stream-aquifer Interaction. Techniques of Water-Resources Investigations of the United States Geological Survey: Washington, DC, Book 6, Chap. A6, 125.

Swanson SK, Bahr JM. 2004. Analytical and numerical models to explain steady rates of spring flow. Ground Water 42(5): 747-759. 